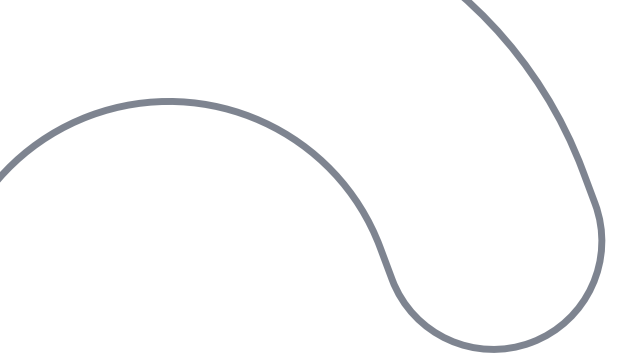

\title{
Processo de prototipagem rápida como alternativa para o re-design de componentes de equipamentos: estudo de caso de uma hélice para exaustor de ar impressa em 3D
}

Rapid prototyping as an alternative for the re-designing of equipment parts:

a case study of a 3D printed propeller for air exhaustion system

\section{Diego Mergener}

Faculdade de Belas Artes | FBAUP - Universidade do Porto

diego.phoenix@hotmail.com

$\mathbf{X}$

\section{Fábio Pinto da Silva}

Universidade Federal do Rio Grande do Sul - UFRGS

fabio.silva@ufrgs.br

\section{PROJËTICA}

\section{COMO CITAR ESTE ARTIGO:}

MERGENER, Diego; SILVA, Fábio Pinto da. Processo de prototipagem rápida como alternativa para o re-design de componentes de equipamentos: estudo de caso de uma hélice para exaustor de ar impressa em 3D. Projética, Londrina, v. 12, n. 1, p. 88-113, 2021.

DOI: 10.5433/2236-2207.2021v12n1p88

Submissão: 12-07-18

Aceite: 09-01-20 
RESUMO: O presente trabalho consiste em um estudo de caso envolvendo a má performance de hélices de uma cabine de exaustão para aplicação de adesivos e produtos à base de solventes, com o objetivo de avaliar e propor, através da impressão 3D, uma melhoria mais barata, rápida e eficiente, que atenda os parâmetros mínimos de exaustão exigidos pelo Ministério do Trabalho. Neste contexto, a pesquisa caracteriza-se como um estudo de natureza aplicada, pois visou levantar dados para o esclarecimento do problema, e posteriormente, estes servirem de subsídios para novas pesquisas. Através de estudos bibliográficos e testes experimentais com protótipos impressos em PLA, neste estudo de caso utilizou-se o instrumento de pesquisa observacional, em que foi possível avaliar a eficácia das hélices impressas e mensurar sua performance de exaustão em relação as hélices fabricadas de metal, comparando o seu grau de eficiência em relação a velocidade de exaustão de ar.

Palavras-chave: Hélice. Impressão 3D. Exaustão de ar.

ABSTRACT: The present work consists of a case study involving the poor performance of propellers from an exhaustion cabin for the application of adhesives and solventbased products, with the objective of evaluating and proposing, through 3D printing, cheaper, faster and more efficient improvements that meets the minimum parameters of exhaustion required by the Ministry of Labor. In this context, the research is characterized as a study of an applied nature, since it aimed to collect data to clarify the problem, and later, serve as subsidies for new research. Through a bibliographic study and experimental tests with printed prototypes in PLA, this case study applied the observational research, through which it was possible to evaluate the effectiveness of the printed propellers and to measure their exhaustion performance in relation to the metal-made propellers, comparing their degree of efficiency in relation to the speed of air exhaustion.

Keywords: Propeller. 3D printing. Air exhaustion. 


\section{INTRODUÇÃO}

Com o passar do tempo, durante a revolução industrial, as máquinas a vapor foram aos poucos substituídas pelas movidas a eletricidade, sendo que nos dias atuais, estão cedendo lugar para as máquinas digitais (CHICCA JÚNIOR, CASTILLO, 2014). Monteiro (2015) afirma que na área do design, a tecnologia de impressão 3D foi aplicada com o objetivo de confeccionar protótipos, pois o uso desta tecnologia proporciona ganho de tempo e velocidade de construção de modelos, se comparados aos métodos anteriormente usados feitos a mão.

Conforme Costa et al. (2015), a (NASA) National Aeronautcs and Space Administration recentemente havia divulgado que levaria impressoras 3D para o espaço, com o objetivo de fabricar em tempo real peças e ferramentas que precisassem ser repostas. A impressora 3D é uma tecnologia que foi desenvolvida na década de 80 , com o objetivo de prototipar artefatos rapidamente e que atualmente, vem sendo utilizada também na educação (LEMKE; SIPLE; FIGUEIREDO, 2016). Conforme Aguiar e Yonezawa (2014) explicam, a técnica conhecida nos dias atuais como impressão 3D teve a primeira patente publicada em março de 1986. Desde esta época, muitos modelos de impressoras vêm surgindo, mostrando novas formas de prototipar artefatos rapidamente.

Costa et al. (2015) afirmam ainda que a prática de impressão 3D pode facilitar e reduzir o tempo dos consertos de produtos, pois isto é hoje uma das reclamações de consumidores em geral. O presente artigo tem como objetivo avaliar e propor uma melhoria de hélices a partir da impressão 3D, utilizando o design como agente norteador para a prototipagem de uma solução mais barata, rápida e eficiente, que se enquadre nos parâmetros mínimos de segurança exigidos pelo Ministério do Trabalho. 


\section{ESTUDO DE CASO DE EXAUSTOR DE AR EM CABINE PARA APLICAÇÃO DE} ADESIVO

Este estudo de caso, se trata de um problema identificado em uma cabine para aplicação de adesivo localizada no Laboratório de Modelagem de Calçados da Universidade Feevale. Esta cabine, é da empresa Exclusive, modelo NS 0001, possui uma área de trabalho para aplicação de adesivo, como pode ser visto na Figura 01.

Figura 1- Cabine de exaustão utilizada no estudo de caso.

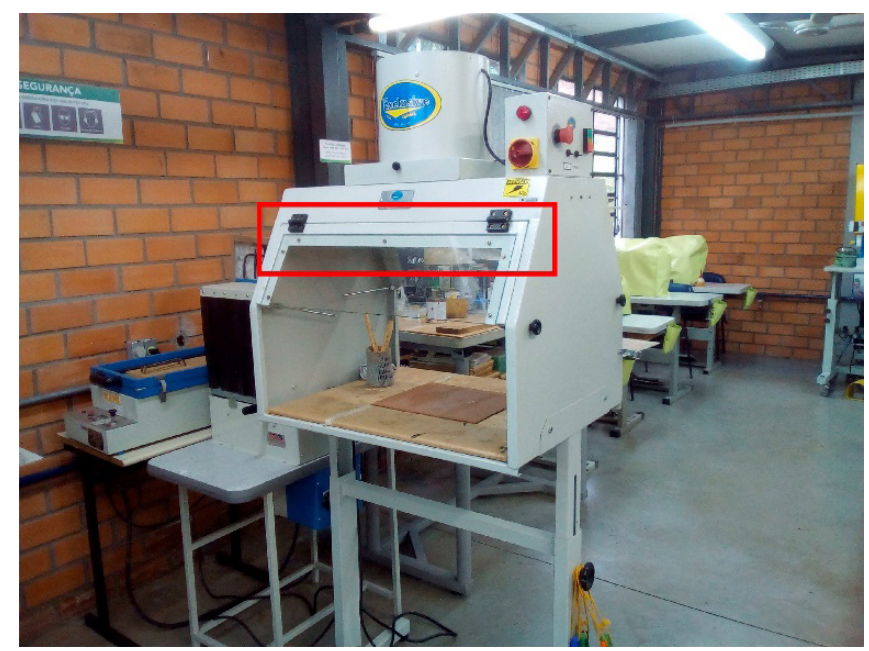

Fonte: Elaborado pelos autores

Entre a área de serviço e o impulsor com a hélice para exaustão do ar contendo os vapores dos adesivos a base de solvente como mostrado em destaque na Figura 1, a cabine possui um filtro com carvão ativado para filtragem de partículas sólidas. Em uma das fiscalizações periódicas feitas pelo engenheiro e técnicos da segurança do trabalho da Universidade Feevale, identificaram, através de um anemômetro, que a evacuação do ar de dentro da cabine não estava sendo executada corretamente. 
Após a medição da velocidade de exaustão, o engenheiro concluiu que a cabine não estava eliminando o ar conforme os parâmetros mínimos apresentados por Vieira (2002) na Tabela 1. Durante a medição, o valor apontado pelo anemômetro em uma altura de aproximadamente $45 \mathrm{~cm}$ da superfície para aplicação dos produtos químicos foi de $0,1 \mathrm{~m} / \mathrm{s}$ com o filtro de carvão ativado entre a área de trabalho e as hélices de exaustão. Retirando o filtro, o valor medido foi de $0,2 \mathrm{~m} / \mathrm{s}$, ou seja, com ou sem a influência do filtro de carvão ativado, a exaustão do ar de dentro da cabine não está nos parâmetros mínimos conforme Vieira (2002). Em termos de valor utilizado como parâmetro para justificar a boa exaustão do ar feita pela hélice da cabine analisada, de acordo com o engenheiro da segurança do trabalho, usa-se o valor médio de 0,7 m/s. Este valor é com base em valores apresentados por Vieira (2002) que, por sua vez, corresponde a média dos valores 0,50 e 1,0 m/s considerados aceitáveis em relação a boa exaustão do ar contendo vapores de produtos químicos como adesivos e solventes, de acordo com o captor tipo de cabine (enclausurante). A Tabela 1 mostra os valores mencionados.

Tabela 1 - Parâmetros base para boa exaustão de ar.

\begin{tabular}{|c|c|c|}
\hline $\begin{array}{c}\text { Classe de Risco } \\
\text { (Tabs. 2 e 3) }\end{array}$ & $\begin{array}{c}\text { Captor Tipo Cabine } \\
\text { (enclausurante) }\end{array}$ & $\begin{array}{c}\text { Exaustão Lateral } \\
\text { (fresta/multifresta) (1) }\end{array}$ \\
\hline $\mathrm{A}-1 ; \mathrm{A}-2$ & $0,50-1,0 \mathrm{~m} / \mathrm{s}$ & $0,8-1,0 \mathrm{~m} / \mathrm{s}$ \\
\hline $\mathrm{A}-3 ; 13-1 ; 13-2 ; \mathrm{C}-1$ & $0,4-0,8 \mathrm{~m} / \mathrm{s}$ & $0,5 \mathrm{~m} / \mathrm{s}$ \\
\hline $13-3 ;$ C-2 $;$ D-1 & $0,4 \mathrm{~m} / \mathrm{s}$ & $0,4 \mathrm{~m} / \mathrm{s}$ \\
\hline $\mathrm{A}-4 ;$ C-3 $; \mathrm{D}-2$ & $0,3 \mathrm{~m} / \mathrm{s}$ & $0,3 \mathrm{~m} / \mathrm{s}$ \\
\hline $13-14 ;$ C-4 $;$ D-3 $;$ D-4 & $(2)$ & $(2)$ \\
\hline
\end{tabular}

Fonte: Vieira, 2002 p. 48.

De acordo com Eletrobrás, um sistema de ventilação é constituído por ventilador, dutos e elementos auxiliares. Como elemento auxiliar, o equipamento utilizado como estudo de caso neste artigo, utiliza um filtro contendo carvão ativado para remover particulado sólido (VENTILADORES..., 2009). 
Conforme Eletrobrás explica, a diferença entre ventilador e exaustor acontece quando: se o ar é empurrado, o equipamento deve ser chamado de ventilador. Já quando o ar é puxado, chamamos de exaustor (VENTILADORES..., 2009). No estudo de caso abordado nesta pesquisa, o objeto de estudo, se trata de uma hélice de exaustor, pois esta executa a função de puxar o ar contendo os vapores de produtos químicos tais como adesivos e solventes para fora da cabine. Conforme Vieira (2002) explica, o ventilador é o item responsável pelo suprimento da energia necessária para adquirir um fluxo ideal na execução das atividades. Vieira (2002) comenta ainda, que para a escolha do ventilador mais adequado ao projeto que ser desenvolvido, se deve considerar alguns fatores como: tipo de poluente, localização do ventilador, eficiência do equipamento, densidade e temperatura das misturas exauridas. Em relação ao último item mencionado, Vieira (2002) destaca que os ventiladores podem apresentar dois tipos: ventiladores axiais utilizados normalmente em ventilação geral diluidora e ventiladores centrífugos, cuja destinação é a ventilação exaustora. Levando em consideração as afirmações de Vieira (2002), este estudo de caso se direciona na avaliação e prototipação de hélices de um ventilador tipo centrífugo, pois seu destino é a ventilação exaustora. A Figura 2 apresenta as partes que compõem um ventilador.

Figura 2 - Partes que um ventilador é composto.

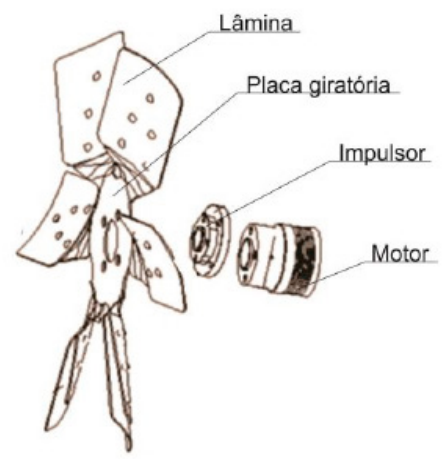

Fonte: Cory 2005 (apud CHECHI, 2014). 
Como alternativa mais barata e rápida para a solução do problema levantado pelo engenheiro e técnicos da segurança do trabalho, se propõem utilizar os recursos da impressão 3D.

\section{MATERIAIS E MÉTODOS}

Para facilitar o entendimento das etapas e processos percorridos durante esta pesquisa, a Figura 3 mostra o fluxo operacional percorrido para a obtenção dos resultados apresentados ao final deste artigo.

Figura 3 - Fluxo operacional percorrido durante a elaboração da hélice.

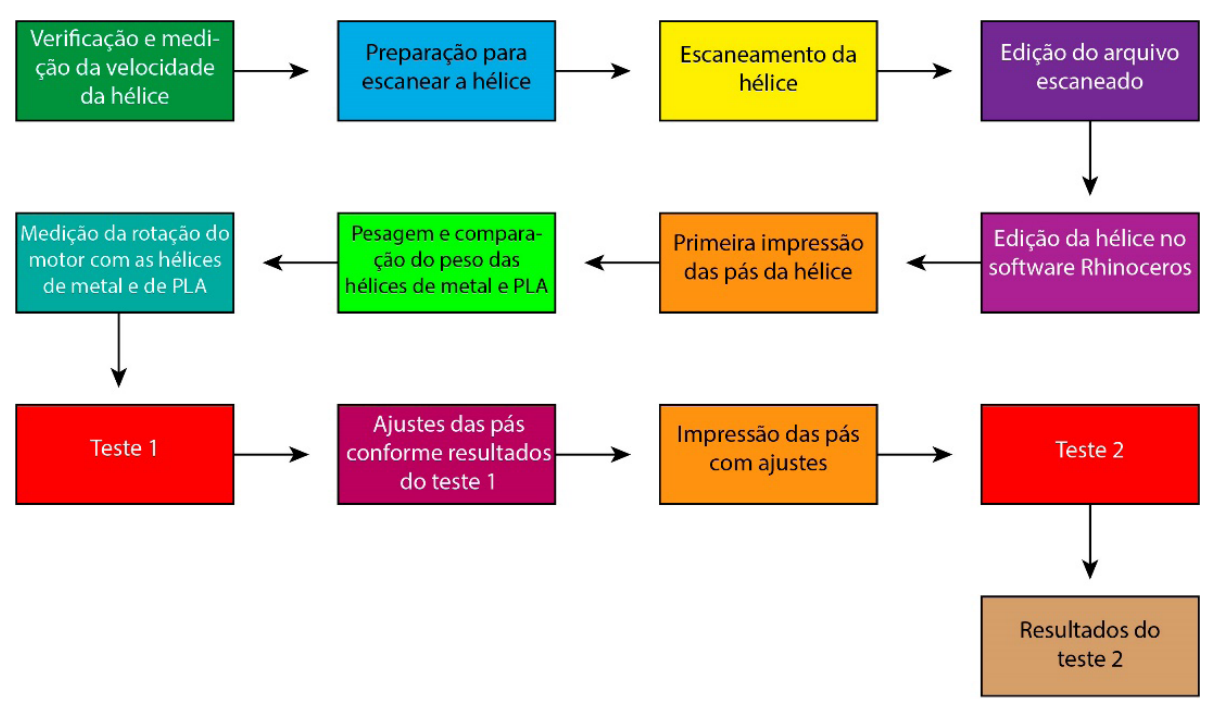

Fonte: Elaborado pelos autores

Iniciou-se com a verificação e medição da velocidade de exaustão da hélice. Para medição desta velocidade de escoamento de ar provocado pela ventoinha, foi utilizado um anemômetro tipo ICEL Manaus AN - 3010. As hélices de metal 
foram levadas até o LDSM (Laboratório de Design e Seleção de Materiais) da UFRGS (Universidade Federal do Rio Grande do Sul) para que fossem escaneadas os seus perfis. Para o escaneamento da hélice, utilizou-se um pó em spray branco, pois como a superfície da hélice é refletiva, o laser não escanearia o objeto corretamente.

O escaneamento da hélice se fez no Digimill 3D, marca Tecnodrill, que se utiliza de cabeçotes emissores de laser pontual, modelo Conoprobe 1.000, da marca Optimet (SILVA, 2011). Suas coordenadas e ajustes foram feitos através do programa Digiform, pois neste programa, foi ajustado o escâner a pegar o ponto mais alto da hélice para melhor interpretar o sinal da superfície utilizando uma resolução de escaneamento de 0,1 mm (resolução entre pontos e linhas).

Após o escaneamento da hélice, o arquivo gerado pelo escâner foi importado para o Geomagic Studio 2013. Neste programa de edição, a nuvem de pontos gerada pelo escaneamento da hélice foi submetida a remoção de excesso de pontos na malha para favorecer a diminuição do tamanho do arquivo. Foram feitas correções e suavizações nas bordas da hélice, a fim de melhorar seu acabamento. O arquivo ajustado no Geomagic foi importado para o Rhinoceros com o objetivo de aplicar espessura a malha gerada.

Para a edição da hélice foi utilizado o software Rhinoceros, pois este, segundo Pires (2010), opera com NURBS (Non Uniform Rational B-spline) podendo modelar e editar as curvas, superfícies e sólidos não regulares com precisão. Para a impressão das pás, utilizou-se uma impressora Makerbot Replicator 3D Printer 5th Generation localizada no Centro de Design da Universidade Feevale.

Após finalizada a impressão, a fim de comparar as densidades das hélices de metal e as impressas em PLA, utilizou-se uma balança de precisão analítica Adventure Ohaus, modelo ARC 120 localizada na Oficina Tecnológica da Universidade Feevale. Como as hélices possuem pesos e materiais diferentes, afim de medir a 
rotação do motor com cada uma, usou-se um tacômetro tipo pistola modelo MDT - 2244․ Depois das medições da rotação, ajustes finais foram feitos para uma nova impressão do protótipo com base em resultados obtidos com o primeiro teste e, posteriormente, foi avaliada a sua performance.

\section{FUNDAMENTAÇÃO TEÓRICA}

\subsection{Manufatura Aditiva}

Hoje em dia, quando se fala de impressão 3D rapidamente se subentende que se trata de uma máquina que é capaz de imprimir objetos a partir de material plástico derretido e deposto camada por camada. Segundo Aguiar (2016) a tecnologia conhecida nos dias atuais como impressão 3D, também é conhecida como manufatura aditiva, pois a matéria utilizada na impressão dos artefatos é aplicada gradualmente até finalizar a construção do objeto.

De acordo com Nery et al. (2016) atualmente a impressão 3D é aplicável a materiais como polímeros e metais, em que a lógica de impressão consiste no movimento de um cabeçote que reproduz as coordenadas de um objeto a partir de comandos de computador. Em relação ao uso de materiais poliméricos, o cabeçote extrusor funde o material plástico e o deposita em camadas em um processo denominado FDM (Modelagem por Fusão e Deposição).

O processo de deposição por material depositado (Fused Deposition Modeling - FDM) trata-se de um processo em que o material em estado plástico é depositado em uma plataforma por um extrusor (MONTEIRO, 2015). Uma vantagem deste método de deposição de material, é a grande flexibilidade de materiais compatíveis que se podem utilizar, sendo os mais comuns os filamentos termoplásticos de ABS e PLA (MONTEIRO, 2015). 
Conforme Monteiro (2015) explica, nos processos tradicionais de confecção de protótipos, geralmente são necessários investimentos iniciais referentes a construção de moldes ou gabaritos, sendo os valores destes diluídos nas séries da produção. O contrário acontece com a impressão 3D, pois independentemente da quantidade de peças, o custo sempre será o mesmo devido a não necessidade do desenvolvimento de moldes para cada peça. Ainda sobre a flexibilidade do uso das impressoras 3D, Monteiro (2015) especifica que como as impressoras são automatizadas, não necessitando de moldes ou gabaritos, fica fácil fabricar peças diferentes apenas trocando o material e alterando a programação.

\subsection{Hélice (Ventoinha)}

Em relação ao significado de o que é uma ventoinha, segundo o Dicionário Aurélio, consiste em um aparelho com uma roda possuindo pás com forma helicoidal, desenvolvido para ventilar um espaço. O que muitos não sabem, é que as pás possuem esta forma para melhor exercer o trabalho que foram projetadas (VENTOINHA ..., 2017).

De acordo com Chechi (2014), as lâminas dos ventiladores são modeladas para operarem com um padrão de fluxo, e normalmente são curvas e desenvolvidas para as diferenças de pressão. Conforme Chechi (2014) explica, a interação das pás com o escoamento de ar ocorre quando a energia cinética é transportada do fluxo para a superfície da pá da ventoinha. Sendo assim, os desenhos das pás são desenvolvidos com o objetivo de ampliar a transferência de ar (CHECHI, 2014).

No caso das hélices analisadas neste estudo de caso, aparentemente, durante o planejamento da cabine, a equipe desenvolvedora considerou que 4 pás seriam suficientes para a evacuação do ar. Porém, de acordo com os resultados da avaliação realizada com o anemômetro, as 4 pás que compõem o jogo de hélices não estão apresentando uma boa performance. 
Projética, Londrina, v. 12, n. 1, p. 88-113, março 2021

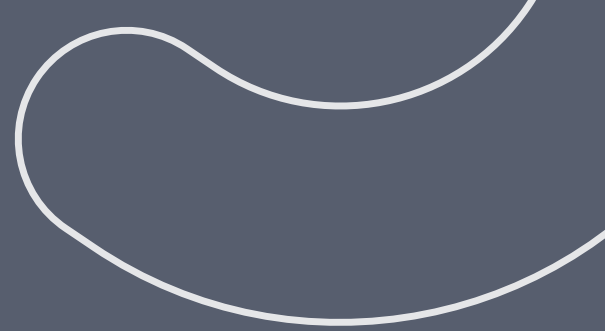

Ainda sobre a flexibilidade do uso das impressoras 3D, Monteiro (2015) especifica que como as impressoras são automatizadas, não necessitando de moldes ou gabaritos, fica fácil fabricar peças diferentes apenas trocando o material e alterando a programação. 
Pires (2010) comenta que os perfis aerodinâmicos comumente usados para asas de aeronaves e para aerogeradores são os do tipo denominados NACA (National Adrisory Committee for Aeronautics) ou (Comitê Nacional para Aconselhamentos sobre Aeronáutica). Pires (2010) complementa dizendo que os perfis NACA são identificados por algarismos que representam as suas relações geométricas. Chechi (2014) diz que os perfis NACA são desenvolvidos levando em consideração uma série de relações de geometria intrínseca no perfil.

\subsection{Desenvolvimento dos Estudos}

\subsubsection{Escaneando a hélice metálica objeto de estudo}

Para iniciar os estudos com a hélice utilizando a tecnologia de impressão 3D, se fez seu escaneamento, com o objetivo de imprimi-la em outro material (PLA) e testar sua performance em relação ao material original em que a hélice é feita, ou seja, metal. A digitalização da hélice foi feita no LDSM (Laboratório de Design e Seleção de Materiais) da UFRGS (Universidade Federal do Rio Grande do Sul).

Para o escaneamento da hélice ter bons resultados, utilizou-se um pó em spray branco para cobrir toda a superfície como mostra a Figura 4, pois esta consiste em uma superfície refletiva, o que ocasionaria um mal resultado no final do processo.

Figura 4 - Preparação da hélice e escaneamento.

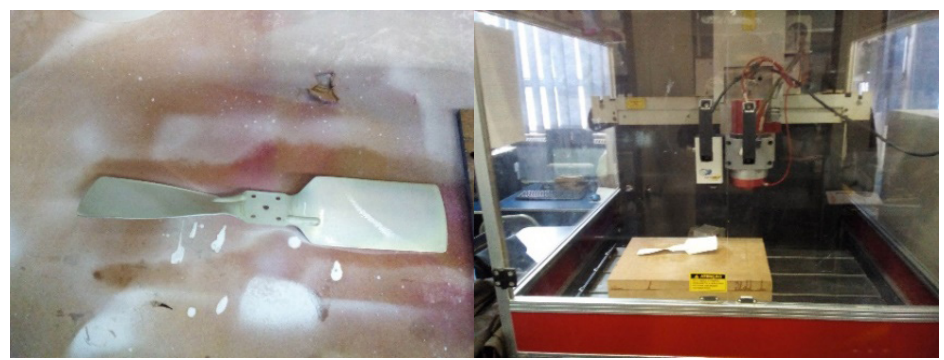

Fonte: Elaborado pelos autores 
O escaneamento foi feito através do Digimill 3D, como descrito no tópico de materiais e métodos. A resolução utilizada durante o escaneamento foi de 0,1 mm (resolução entre pontos e linhas), por este motivo, o tempo final de escaneamento da hélice girou em torno dos 60 minutos. De acordo com Silva (2011), o Digimill 3D trata-se de um equipamento CNC híbrido, em que se pode trabalhar como uma fresadora CNC ou como um scanner tridimensional a laser. Ainda sobre as características do Digimill 3D, Silva (2011, p. 74) explica que "este sistema trabalha com comprimento de onda de $655 \mathrm{~nm}$, potência máxima de $1 \mathrm{mw}$, e tem por característica adquirir até 1.000 pontos por segundo".

Finalizado o escaneamento da hélice, conforme Silva (2011) comenta, são obtidos arquivos de texto com pontos da superfície do objeto escaneado em que estes pontos são descritos em forma de coordenadas $(x, y, z)$, definindo assim a nuvem de pontos do objeto.

\subsubsection{Ajustes da hélice após escaneamento}

Após finalizado o escaneamento da hélice, o arquivo de texto gerado contendo as coordenadas da nuvem de pontos do objeto foi importado para o Geomagic Studio 2013. Segundo Silva (2006), a primeira etapa do processamento da nuvem de pontos é a exclusão dos pontos que alteram a silhueta da nuvem de pontos capturada, que por sua vez, acabam aumentando o tamanho do arquivo desnecessariamente. Além da exclusão dos pontos, ao gerar a malha, normalmente aparecem aberturas que devem ser fechados para melhor acabamento da malha. Segundo Silva (2006) estas descontinuidades devem ser corrigidas. O autor afirma ainda que a partir de uma nuvem de pontos filtrada após a remoção dos pontos desnecessários, é possível construir uma malha com maior qualidade, como pode ser visto na Figura 5. 
Figura 5 - Malha após os ajustes.

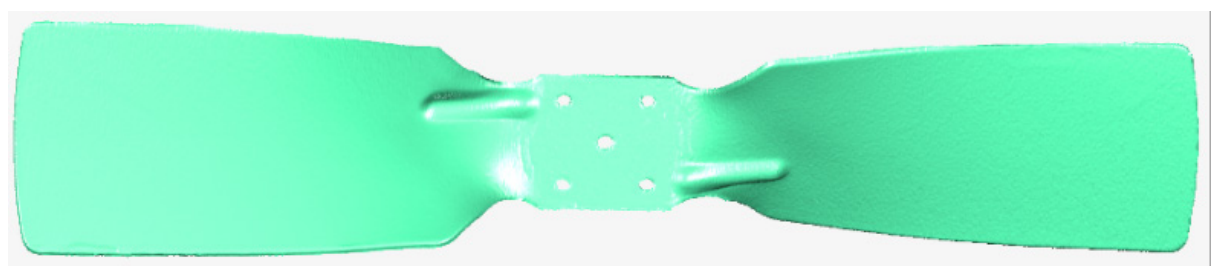

Fonte: Elaborado pelos autores

Utilizando as ferramentas do Geomagic 3D Studio, estes acabamentos foram executados, deixando a malha gerada a partir da nuvem de pontos melhor acabada e pronta para a importação para o próximo programa que irá gerar a espessura da malha obtida. Após finalizados os ajustes na malha, o arquivo foi importado do Geomagic 3D Studio para o software Rhinoceros 4. Utilizando as ferramentas do Rhinoceros para geração de espessura, obteve-se o resultado como pode ser visto na Figura 6. Para a hélice, utilizou-se o valor de $3 \mathrm{~mm}$ como espessura inicial para o teste após impressão. No centro da hélice, em que esta é encaixada no impulsor do motor, foi removido 1,5 $\mathrm{mm}$ da espessura, pois se pretende imprimir 4 pás e encaixá-las posteriormente. Esta redução facilitará o encaixe das pás no suporte acoplado no motor, porém, prevê-se que esta redução ocasionará em uma maior fragilidade das pás na região entre os orifícios de encaixe e o perfil da hélice.

Figura 6 - Hélice com espessura obtida no Rhinoceros.

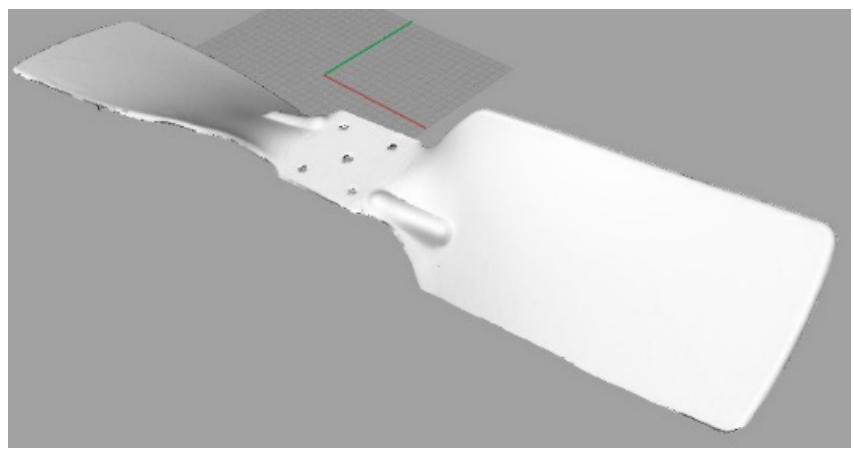

Fonte: Elaborado pelos autores 
Terminado o processo de geração de espessura da malha, uma adequação dimensional foi feita para permitir que o objeto coubesse na área de impressão, afim de adaptá-lo para as limitações da impressora que se utilizará para sua materialização. O objeto foi partido ao meio como forma estratégica utilizada para impressão, a fim de reduzir seu tamanho e de ter maior possibilidade de orientações para a qualidade de impressão. A Figura 7 mostra a hélice partida ao meio com um suporte na sua base.

Figura 7 - Hélice pronta para impressão.

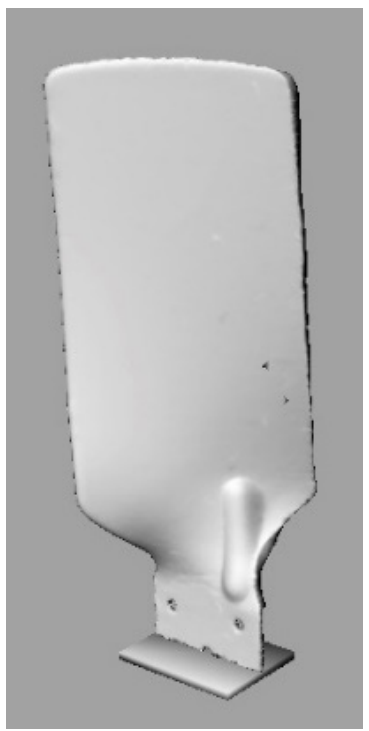

Fonte: Elaborado pelos autores

Ao partir o objeto ao meio e colocá-lo de pé para obter melhor acabamento superficial durante a impressão, a altura total do objeto ficou em $130 \mathrm{~mm}$. O suporte na sua base possui as dimensões de $29 \times 24 \times 17 \mathrm{~mm}$ e foi colocado com o objetivo de dar maior sustentação ao objeto, pois em testes iniciais, ocorreram erros e perda de material devido a instabilidade do objeto durante a sua impressão. Finalizado a edição da hélice no Rhinoceros, o objeto foi salvo em formato STL (Stereolithography), pois este formato de arquivo que as impressoras 3D oferecidas pelo mercado normalmente utilizam para imprimir. 


\subsubsection{Imprimindo o protótipo}

A impressão do protótipo foi feita em uma impressora Makerbot Replicator 3D Printer 5th Generation, localizada no Centro de Design da Universidade Feevale. Esta impressora utiliza filamento de PLA de 1,75 mm e o cabeçote extrusor possui diâmetro de 0,3 mm. Sua área máxima de impressão é de 25 × 20 × 20 (eixos X, Y, Z) aquecendo o filamento até $215^{\circ} \mathrm{C}$.

Optou-se em imprimir somete 2 pás por vez, pois, como a impressora se encontra sobre um ambiente que não possui qualquer controle de temperatura, há chances de ocorrem erros de impressão. Segundo as estatísticas mostradas pelo programa sobre o tempo estimado para finalização da impressão, as 2 pás levariam cerca de 03:41:12 horas para serem concluídas. A Figura 8 mostra as 2 primeiras pás finalizadas ainda com o suporte criado durante a impressão.

Figura 8 - Primeiras pás finalizadas com suporte de impressão.

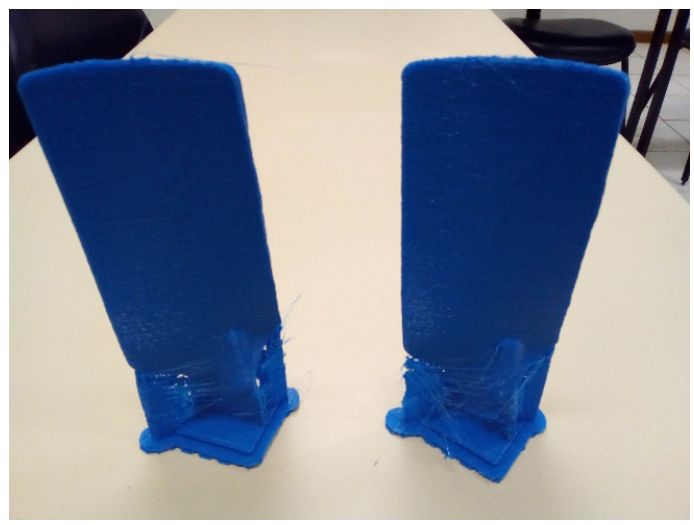

Fonte: Elaborado pelos autores

Após a impressão de todas as pás que juntas formam as hélices, se removeram os suportes e se fizeram acabamentos superficiais com lixa para remoção total dos resíduos dos suportes utilizados para a impressão. 


\section{TESTE DO PROTÓTIPO}

Impressas as 4 pás da hélice, utilizou-se uma balança de precisão analítica Adventure Ohaus modelo ARC 120, com capacidade máxima de pesagem de 3100 g e mínima de 0,5 g, para pesar e comparar os pesos das pás impressas em PLA e as 2 hélices de metal. Entre os valores obtidos durante a pesagem das hélices, as de metal pesaram 187,25 g e as de PLA pesaram 78, 43 g. Nota-se uma grande diferença de pesos entre a hélice de metal e a de PLA devida a baixa densidade do material plástico. O próximo passo foi medir a rotação do motor, pois o objetivo era verificar se estas disparidades de pesos entre as hélices ocasionariam em mudanças de velocidades de rotação. Para a medição da rotação do motor, utilizou-se um tacômetro tipo pistola modelo MDT - 2244a.

As hélices de metal foram as primeiras a serem utilizadas para medição de rotação do motor. Como resultado final, obteve-se a velocidade de 1.722 rpm como velocidade de rotação do motor. Após medição das hélices metálicas, se montaram as hélices de PLA no suporte que é encaixado no motor como pode ser visto na Figura 9.

Figura 9 - Protótipo pronto para medição de rotação do motor.

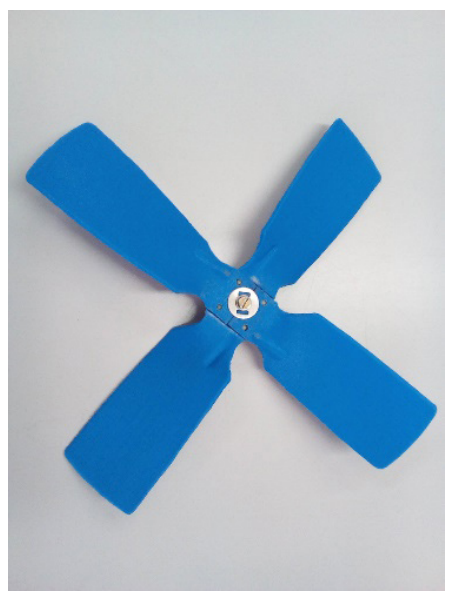

Fonte: Elaborado pelos autores 
Ao medir a rotação das hélices impressas em PLA, após 5 segundos em movimento, 3 das 4 pás romperam-se, como pode ser visto na Figura 10. Como descrito anteriormente, havia a hipótese de que devido a espessura de 1,5 mm deixada no centro das pás para que pudessem ser encaixadas no suporte do motor poderiam se romper durante o teste. Entretanto com a rotação do motor as pás romperam-se devido a área central estar frágil demais. De acordo com Hibbeler (2004) as pás que compõem a hélice romperam-se devido as tensões exercidas durante o movimento até que o material quebrasse com a tensão de ruptura.

Hibbeler (2004) comenta ainda que a ruptura em um material pode ocorrer em uma imperfeição ou microtrinca que a partir desta fragilidade existente no material, a ruptura pode ocorrer e se espalhar rapidamente.

Levando em consideração a afirmação de Hibbeler (2004), é possível afirmar que além da pouca espessura deixada na região central das pás, a ruptura destas durante o teste pode ter ocorrido devido a uma imperfeição durante a impressão, pois como o processo FDM é a partir da deposição de material por camadas, estima-se que exista pequenos locais na estrutura das pás que possa ter imperfeições de impressão.

Figura 10 - Resultado do teste de rotação do motor com as hélices de PLA.

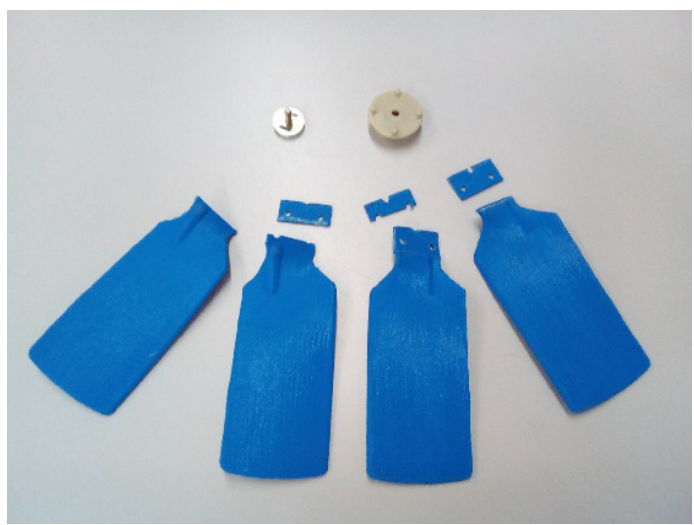

Fonte: Elaborado pelos autores 
Os rompimentos nas pás ocorreram na fronteira entre a parte central, com 1,5 mm de espessura e o restante do perfil da pá com $3 \mathrm{~mm}$ de espessura. Machado e Soares (2011) explicam que em cantos retos de ângulo de $90^{\circ}$, a elevada concentração de tensão que surge da disposição geométrica influencia o surgimento de trincas, deformações plásticas ou até mesmo a ruptura da estrutura que está sendo submetida a tais tensões. É possível dizer que devido aos cantos retos existentes entre o rebaixo da área central das pás para montagem e o restante do perfil, somados com alguma fragilidade existente na estrutura das pás decorrente da impressão, podem ter contribuídos para a quebra do protótipo durante o teste. Por este motivo, para um segundo teste, optou-se em aumentar a espessura central de 1,5 $\mathrm{mm}$ para $2 \mathrm{~mm}$, assim como suavizar os cantos, como pode ser visto na Figura 11.

Figura 11 - Aumento de espessura da área central de montagem das pás.

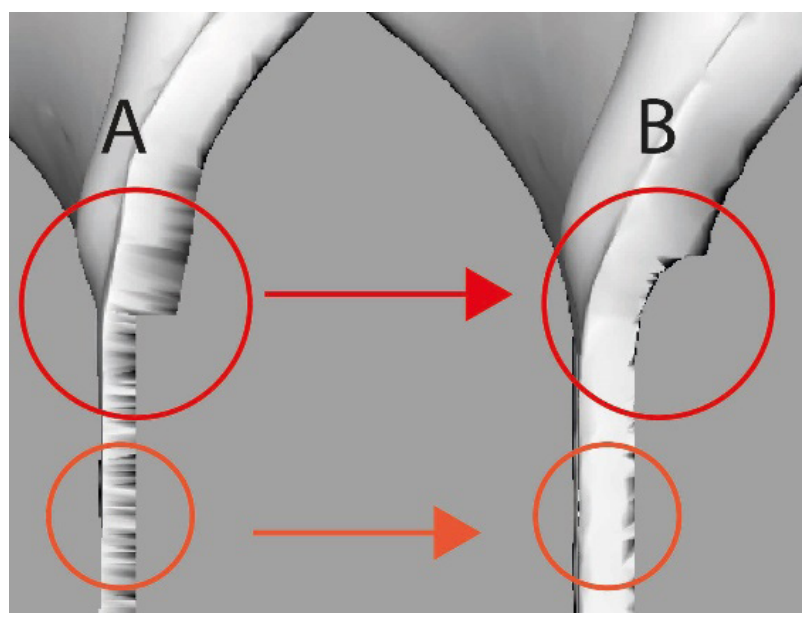

Fonte: Elaborado pelos autores

A Figura 11 mostra a suavização da fronteira do rebaixo da área central da pá com o restante do perfil, com o objetivo de suavizar os cantos vivos para uma redução de tensão nos locais críticos (MACHADO E SOARES, 2011). Com os 
ajustes efetuados, as novas pás que compõem as hélices foram impressas, levando desta vez, 04:22:00 horas para imprimir 2 das 4, ou seja, cerca de aproximadamente 02:11:00 horas para imprimir somente uma pá. Estas por sua vez, foram montadas no suporte que vai acoplado no rotor do motor, como mostra a Figura 12.

Figura 12 - Hélices montadas e prontas para os testes.

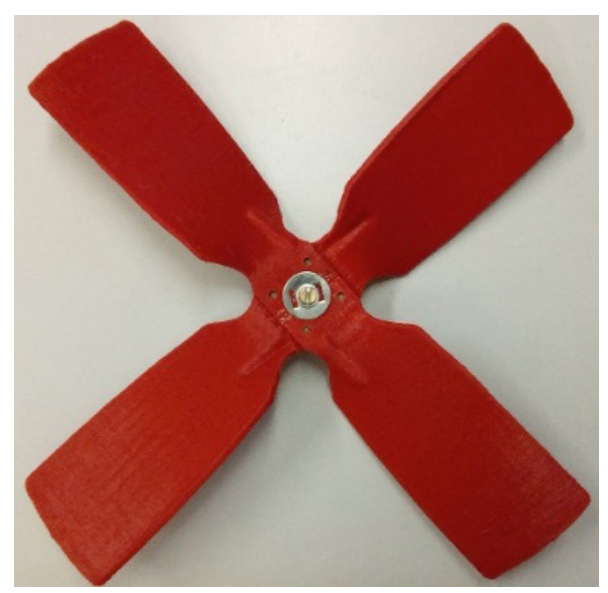

Fonte: Elaborado pelos autores

Após montadas as hélices no impulsor, se mediu a velocidade de rotação do motor, sendo que desta vez, devido aos ajustes efetuados, as hélices não se romperam. O valor medido com o tacômetro foi de 1.727 rpm, ou seja, basicamente a mesma velocidade de rotação medida com as hélices de metal. Isto significa que o peso das hélices prototipadas, embora seja menor que as de metal, não interferem na performance rotativa do motor. Ao avaliar a performance das hélices agora com os ajustes, nas mesmas condições em que foi analisada a eficiência das hélices de metal, medindo a velocidade de exaustão a $45 \mathrm{~cm}$ de altura sem o filtro de carvão ativado, obteve-se o valor de 0,9 m/s no anemômetro. As hélices feitas de PLA na impressora 3D mostraram ser mais eficientes do que as de metal, pois alcançaram um valor de velocidade de exaustão dentro dos parâmetros exigidos pelo Ministério do Trabalho, que é de no mínimo 0,5 m/s conforme mostrado na Tabela 1 . 


\section{CONCLUSÃO}

O escaneamento aliado à impressão 3D mostrou ser uma ótima ferramenta para análise e resolução de problemas mecânicos. Este tipo de recurso não somente serviu para avaliar a eficácia de um objeto feito de um material diferente, como auxiliou no esclarecimento das variáveis que cercavam o problema identificado como a rotação do motor. Com base nos resultados obtidos a partir dos testes efetuados com os protótipos de hélices feitos de PLA, conclui-se que as hélices prototipadas, mesmo apresentando geometria e tamanho iguais às de metal, tendo somente o material, a espessura e o peso diferente, mostraram ser mais efetivas em relação à velocidade de exaustão. Uma variável identificada, que pode ter contribuído na performance das hélices de PLA, foi a rugosidade da superfície. A rugosidade da superfície decorrente da impressão pode ter contribuído significativamente para aumentar a performance das hélices feitas de PLA, pois ela apresenta pequenas depressões. O atrito das pás com o ar é diferente se comparado as de metal, cuja superfície é lisa. Conclui-se, ainda, que a impressão 3D pode ser uma ótima ferramenta de estudo e solução de baixo custo para problemas mecânicos, em que se possa propor novas peças ou artefatos capazes de solucionar os problemas identificados.

Cabe ainda apontar que, nos testes realizados, o desempenho alcançado se comportou de forma satisfatória, porém, testes de longa duração ainda devem ser realizados. Visto que a resistência mecânica dos objetos construídos por esse tipo de impressão com o material PLA é relativamente baixa, pode haver uma fragilidade de uso em grandes períodos de tempo e em peças de equipamentos feitas deste material. 
Conclui-se, ainda, que a impressão 3D pode ser uma ótima ferramenta de estudo e solução de baixo custo para problemas mecânicos, em que se possa propor novas peças ou artefatos capazes de solucionar os problemas identificados. 
Para aumentar ainda mais a performance, sugere-se para novas pesquisas, o acréscimo de uma textura diferente da gerada originalmente na impressão sobre a superfície das hélices. Segundo Chechi (2014), a aplicação de texturas, por alterar as características superficiais de um material, influencia também na performance dos produtos quando estes são utilizados. Chechi (2014) apresenta ainda o exemplo do caso da ventoinha Silent Eagle feita pela Shakoon, no qual a empresa desenvolvedora obteve bons resultados colocando uma textura sobre as pás da hélice inspirada na bola de golf.

Sugere-se, ainda, que tanto os métodos do estudo efetuado neste trabalho como os seus resultados sejam utilizados no ensino superior como objeto de aprendizagem em disciplinas como Fenômenos de transporte e Resistência dos materiais. O objetivo deste trabalho de pesquisa e experimentação foi alcançado, mostrando a flexibilidade da impressão 3D para prototipar e avaliar a eficácia de artefatos quando impressos em PLA, assim como, foi demostrado que por meio da impressão 3D se pode propor melhorias em máquinas e equipamentos. 


\section{REFERÊNCIAS}

1. AGUIAR, Leonardo De Conti Dias. Um processo para utilizar a tecnologia de impressão 3D na construção de instrumentos didáticos para o ensino de ciências. 2016. Dissertação (Mestrado em Educação para a Ciência) - Faculdade de Ciências, Universidade Estadual Paulista, Bauru, 2016.

2. AGUIAR, Leonardo De Conti Dias; YONEZAWA, Wilson Massashiro. Construção de instrumentos didáticos com impressora 3D. In: SINTECT - SIMPÓSIO NACIONAL DE ENSINO DE CIÊNCIAS E TECNOLOGIA, 4., Ponta Grossa, PR. Anais eletrônicos [...]. Ponta Grossa: UFTPR, 2014. Disponível em: http:// sinect.com.br/anais2014/anais2014/artigos/tic-no-ensino-aprendizagem-deciencias-e-tecnologia/01409583389.pdf. Acesso em: 15 maio 2017.

3. CHECHI, Florence Endres. Design e avaliação aerodinâmica da topologia geométrica superficial de ventoinhas. 2014. Dissertação (Mestrado em Design) - Escola de Engenharia, Faculdade de Arquitetura, Universidade Federal do Rio Grande do Sul, Porto Alegre, RS, 2014.

4. CHICCA JÚNIOR, Natal Anacleto; CASTILLO, Leonardo Gómez. Impressão 3D na cultura do design contemporâneo. Blucher Design Proceedings, São Paulo, SP, v. 1, n. 4, p. 2344-2353, 2014.

5. COSTA, Cristiano Soares da; MIGUEL, Dorcas de Castro Viana; SOUZA FILHO, Edison de; SILVA, Marcus Vinícius Fernandes; MACHADO, Mônica da consolação. Impressão 3D: a tecnologia do momento. Pós em Revista, Belo Horizonte, MG, n. 11, p. 48-52, 2015.

6. HIBBELER, R.C. Resistência dos materiais. 5. ed. São Paulo: Pearson Prentice Hall, 2004. 
7. LEMKE, Raiane; SIPLE, Ivanete Zuchi; FIGUEIREDO, Elisandra Bar de. OAs para o ensino de cálculo: potencialidades de tecnologias 3D. Novas Tecnologias na Educação, Porto Alegre, RS, v. 14, n. 1, jul. 2016. DOI: https://doi. org/10.22456/1679-1916.67355.

8. MACHADO, Vinícius Luiz; SOARES, Gilson Francisco Paz. Análise pelo método dos elementos finitos de um modelo simplificado de parte da estrutura dianteira de uma carroceria de micro-ônibus modelo rodoviário. In: CREEM: Congresso Nacional de Estudantes de Engenharia Mecânica, 18., Erechim, RS, 2011. Anais eletrônicos [...]. Erechim: ABCM, 2011. Disponível em: https:// abcm.org.br/anais/creem/2011/tmc/03.pdf. Acesso em: 15 maio 2017.

9. MONTEIRO, Marco Túlio Ferreira. A impressão 3D no meio produtivo e o Design: um estudo na fabricação de joias. 2015. Dissertação (Mestrado em Design) Universidade do Estado de Minas Gerais, Belo Horizonte, MG, 2015.

10. NERY, M. P.; NOGUeIRA, L. M.; DANA, S. S.; COSTA, Augusto M.; SANTOS JUNIOR, J. A. Avaliação metrológica e superficial de peças poliméricas fabricadas em impressora 3D. In: CONGRESSO BRASILEIRO DE ENGENHARIA E CIÊNCIA DOS MATERIAIS, 22., 2016. Anais [...]. Natal, RN. Natal: CBECiMat, 2016. p. $9850-9858$.

11. PIRES, Júlio César Pinheiro. Estudo de rotor para turbina eólica de eixo horizontal de pequeno porte com aplicação de modelagem e simulação virtual. 2010. Dissertação (Mestrado em Design) - Escola de Engenharia, Faculdade de Arquitetura, Universidade Federal do Rio Grande do Sul, Porto Alegre, RS, 2010. 
12. SILVA, Fábio Pinto da. O uso da digitalização tridimensional a laser no desenvolvimento e caracterização de texturas aplicadas ao design de produto. 2006. Dissertação (Mestrado em Engenharia) - Escola de Engenharia, Universidade Federal do Rio Grande do Sul, Porto Alegre, RS, 2006.

13. SILVA, Fábio Pinto da. Usinagem de espumas de poliuretano e digitalização tridimensional para fabricação de assentos personalizados para pessoas com deficiência. 2011. Tese (Doutorado em Engenharia) - Escola de Engenharia, Universidade Federal do Rio Grande do Sul, Porto Alegre, RS, 2011.

14. VENTILADORES e exaustores: guia básico. Brasília, DF: Eletrobrás, 2009.

15. VENTOINHA. In: AURÉLIO - dicionário Aurélio de português online. Disponível em: https://dicionariodoaurelio.com/ventoinha. Acesso em: 15 maio 2017.

16. VIEIRA, Fernando sobrinho. Ventilação local exaustora em galvanoplastia. Colaboração de Francisco Kulcsar Neto et al. São Paulo, SP: Fundacentro, Ministério do Trabalho e Emprego, 2002. 